\title{
Recomendaciones para la prescripción segura de opioides en el manejo del dolor crónico no oncológico
}

\author{
Emma Verástegui, Ricardo Plancarte, Judith Domínguez, Rubén Burgos, Oscar Arrieta, Carlos Campillo, \\ Miguel Ángel Celis, Manuel De la-Llata, José Halabe, Sergio Islas, Luis Jasso, Alberto Lifshitz, \\ Mucio Moreno, Alejandro Reyes, Guillermo Ruiz-Argüelles, Antonio Soda y Julio Sotelo \\ Academia Nacional de Medicina, Comité de Ética y Transparencia en la Relación Médico-Industria (Cetremi), Ciudad de México, México
}

\begin{abstract}
Resumen
El tratamiento del dolor crónico severo es una meta histórica de la medicina. Los opioides naturales (como la morfina) se han usado por muchos años y la aparición reciente de opioides sintéticos se ha sumado a esta opción terapéutica, sin embargo, el potencial adictivo de estas sustancias obliga a la reglamentación de su uso. Las agencias médicas internacionales recomiendan prudencia en el uso terapéutico de opioides.
\end{abstract}

PALABRAS CLAVE: Tratamiento analgésico. Dolor crónico. Opioides. Adicción a opioides.

\begin{abstract}
The treatment of chronic and severe pain is a principal goal of medicine. Natural opioids have been used for several years, and the recent development of synthetic opioids has increased therapeutic options; however, the addictive potential of these substances obliges the regulation of their use. International agencies recommend prudent rules in the therapeutic use of opioids.
\end{abstract}

KEY WORDS: Pain therapy. Chronic pain. Opioids. Opioid addiction.

El dolor es uno de los problemas médicos más frecuentes y su alivio una meta terapéutica importante; los analgésicos constituyen la piedra angular. El manejo de este síntoma requiere abordaje multimodal de acuerdo con sus características, intensidad y acceso a distintas opciones terapéuticas. Una preocupación para los sistemas de salud a nivel internacional es el adecuado uso de los fármacos, en especial los opioides.

Las bases de tratamiento farmacológico para el dolor crónico fueron propuestas por la Organización Mundial de la Salud en 1986 de acuerdo con la intensidad, legitimando el uso de opioides y su beneficio potencial para el alivio del dolor crónico por cáncer. En México se han realizado esfuerzos importantes para mejorar la disponibilidad de opioides para el alivio del dolor crónico oncológico y en cuidados paliativos.

Sin embargo, en dolor crónico no oncológico, la falta de guías clínicas, el potencial adictivo de estos fármacos, su desvío, uso indebido y el preocupante aumento de muertes por sobredosis en algunos países, ha obligado a las autoridades de salud, agencias reguladoras, organizaciones médicas, comunidad científica, organismos internacionales y compañías farmacéuticas a implementar estrategias coordinadas para promover la prescripción segura y responsable, así como para mitigar los riesgos en el uso de opioides.

El Comité de Ética y Transparencia en la Relación Médico-Industria (Cetremi) de la Academia Nacional de
Fecha de recepción: 03-10-2017

Fecha de aceptación: 27-01-2018

DOI://dx.doi.org/10.24875/GMM.18003760
Gac Med Mex. 2018;154:532-533

Disponible en PubMed

www.gacetamedicademexico.com 
Medicina considera fundamental diseñar un equilibrio para proporcionar fácil acceso a estos fármacos a quienes los necesitan y establecer una estrategia nacional para evitar el riesgo de adicción, desvío, tráfico y uso indebido de opioides adquiridos mediante prescripción lícita, por lo que en concordancia con lo establecido por los Centros para el Control y Prevención de las Enfermedades de Estados Unidos, se suma a sus recomendaciones autorizadas para su transcripción:

No prescribir opioides como tratamiento inicial del dolor crónico (en adultos mayores de 18 años con dolor crónico > 3 meses, excepto en pacientes con cáncer, en cuidados paliativos 0 al final de la vida).

A) Antes de iniciar tratamiento

1. Evaluar el tipo de dolor y la funcionalidad. Utilizar una escala de evaluación validada, por ejemplo, la escala visual análoga (EVA) que tiene la siguiente gradación:

- Del 1 al 10 describe la intensidad del dolor (0 sin dolor-10 el peor dolor que haya sentido)

- Del 1 al 10 describe cuánto ha interferido el dolor con las actividades cotidianas (0 nada-10 no permite hacer nada).

- Del 1 al 10 indica cómo afecta el bienestar (0 nada-10 afecta totalmente el bienestar)

2. Considerar si están indicados analgésicos no opioides, por ejemplo, AINE, tricíclicos, inhibidores de la recaptura de serotonina, anticonvulsivantes, ejercicio, terapia física.

3. Informar al paciente sobre el plan de tratamiento.

- Establecer metas realistas para el alivio del dolor y la funcionalidad con base en el diagnóstico.

- Discutir los beneficios, efectos secundarios, y riesgos (por ejemplo, adicción, sobredosis).

- Establecer los criterios para finalizar o continuar el tratamiento y plan de seguimiento.

- Asegurar el entendimiento y aceptación del paciente del plan de tratamiento.

4. Evaluar los riesgos, daños o uso aberrante.

- Riesgos conocidos: uso de drogas ilegales, uso de medicamentos por razones no médicas, historia de abuso de sustancias o sobredosis, enfermedades mentales.

- Interrogar sobre el uso de medicamentos controlados, opioides o sedantes obtenidos legal o ilegalmente

- Si es posible, realizar tamizaje en orina para determinar la presencia de medicamentos controlados o drogas ilícitas

- Evitar posibles interacciones medicamentosas.

B) Al prescribir: Iniciar lentamente con dosis bajas.

- Iniciar con opioides de liberación inmediata.

- Si es necesario prescribir una dosis mayor a $\geq 90 \mathrm{MME} / \mathrm{día}$, considerar la referencia del paciente a un especialista en dolor.

- Cuando la prescripción es $\geq 50 \mathrm{MME} / \mathrm{día}$, establecer el seguimiento del paciente con mayor frecuencia.

- En caso de dolor agudo, prescribir opioides por un tiempo corto, < 3 días, en raras ocasiones es necesario el tratamiento por más de siete días.

- Instruir al paciente y su familia sobre almacenamiento seguro y desecho de opioides no utilizados.

C) En el seguimiento: Evaluar, ajustar y disminuir.

- Reevaluar riesgos y beneficios una a cuatro semanas después de iniciar.

- Evaluar el dolor y la funcionalidad, comparando con la evaluación inicial. Programar la reevaluación a intervalos regulares.

- Continuar el tratamiento con opioides si existe mejoría clínicamente significativa en el alivio del dolor y función sin riesgos o daños significativos.

- En caso de somnolencia o riesgo de sobredosis, ajustar la cantidad, por ejemplo, disminución de $10 \%$.

- Considerar el apoyo psicosocial.

- Ajustar la dosis individualmente vigilando los datos de supresión.

En pacientes con uso indebido de opioides, se deberán emplear tratamientos con buprenorfina o metadona y apoyo psicológico. 